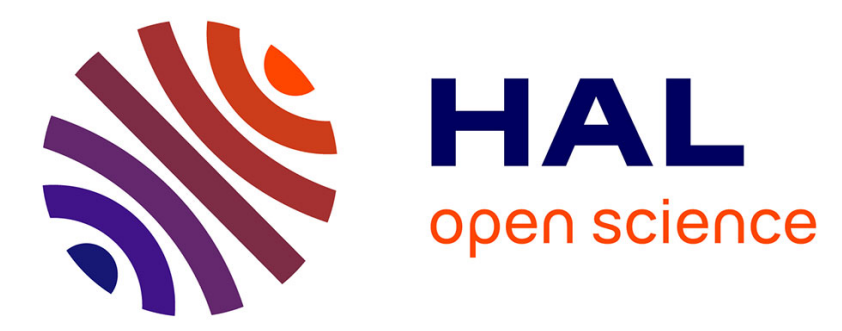

\title{
Large-scale synthesis of single-wall carbon nanotubes by catalytic chemical vapor deposition (CCVD) method
} Jean -François Colomer, C. Stephan, Serge Lefrant, Gustaaf van Tendeloo, Isabelle Willems, Z. Kónya, Antonio Fonseca, Christophe Laurent, Janos B. Nagy

\section{To cite this version:}

Jean -François Colomer, C. Stephan, Serge Lefrant, Gustaaf van Tendeloo, Isabelle Willems, et al.. Large-scale synthesis of single-wall carbon nanotubes by catalytic chemical vapor deposition (CCVD) method. Chemical Physics Letters, 2000, vol. 317, pp. 83-89. 10.1016/S0009-2614(99)01338-X . hal-00949248

\section{HAL Id: hal-00949248 \\ https://hal.science/hal-00949248}

Submitted on 19 Feb 2014

HAL is a multi-disciplinary open access archive for the deposit and dissemination of scientific research documents, whether they are published or not. The documents may come from teaching and research institutions in France or abroad, or from public or private research centers.
L'archive ouverte pluridisciplinaire HAL, est destinée au dépôt et à la diffusion de documents scientifiques de niveau recherche, publiés ou non, émanant des établissements d'enseignement et de recherche français ou étrangers, des laboratoires publics ou privés. 


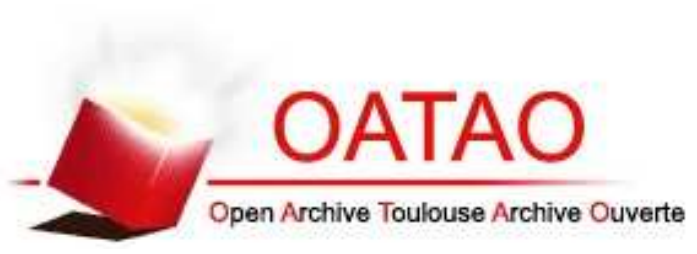

\section{Open Archive TOULOUSE Archive Ouverte (OATAO)}

OATAO is an open access repository that collects the work of Toulouse researchers and makes it freely available over the web where possible.

This is an author-deposited version published in : http://oatao.univ-toulouse.fr/ Eprints ID : 10891

To link to this article : DOI:10.1016/S0009-2614(99)01338-X

URL : http://dx.doi.org/10.1016/S0009-2614(99)01338-X

\section{To cite this version :}

Colomer, Jean -François and Stephan, C. and Lefrant, Serge and Van Tendeloo, Gustaaf and Willems, Isabelle and Kónya, Z. and Fonseca, Antonio and Laurent, Christophe and Nagy, Janos B. Large-scale synthesis of single-wall carbon nanotubes by catalytic chemical vapor deposition (CCVD) method. (2000) Chemical Physics Letters, vol. 317 (n 1-2). pp. 83-89. ISSN 0009-2614

Any correspondance concerning this service should be sent to the repository administrator: staff-oatao@listes-diff.inp-toulouse.fr 


\title{
Large-scale synthesis of single-wall carbon nanotubes by catalytic chemical vapor deposition (CCVD) method
}

\author{
J.-F. Colomer ${ }^{\mathrm{a}, *}$, C. Stephan ${ }^{\mathrm{b}}$, S. Lefrant ${ }^{\mathrm{b}}$, G. Van Tendeloo ${ }^{\mathrm{c}}$, I. Willems ${ }^{\mathrm{a}}$, \\ Z. Kónya ${ }^{a}$, A. Fonseca ${ }^{a}$, Ch. Laurent ${ }^{\text {d }}$, J. B.Nagy ${ }^{\text {a }}$ \\ a Laboratoire de Résonance Magnétique Nucléaire, FUNDP, 61 rue de Bruxelles, B-5000 Namur, Belgium \\ ${ }^{\mathrm{b}}$ IMN, Université de Nantes, BP 32229, F-44322 Nantes cedex 3, France \\ ${ }^{\mathrm{c}}$ EMAT, University of Antwerp (RUCA) Groenenborgerlaan 171, B-2020 Antwerp, Belgium \\ ${ }^{\mathrm{d}}$ Laboratoire de Chimie des Matériaux Inorganiques, ESA CNRS 5070, Université Paul-Sabatier, F-31062 Toulouse cedex 4, France
}

\begin{abstract}
The large-scale production of single-wall carbon nanotubes (SWNTs) is reported. Large quantities of SWNTs can be synthesised by catalytic decomposition of methane over well-dispersed metal particles supported on $\mathrm{MgO}$ at $1000^{\circ} \mathrm{C}$. The thus produced SWNTs can be separated easily from the support by a simple acidic treatment to obtain a product with high yields (70-80\%) of SWNTs. Because the typical synthesis time is $10 \mathrm{~min}, 1 \mathrm{~g}$ of SWNTs can be synthesised per day by this method. The SWNTs are characterized by high-resolution transmission electron microscopy and by Raman spectroscopy, showing the quality and the quantity of products.
\end{abstract}

\section{Introduction}

In addition to the laser evaporation and electric arc discharge techniques, the catalytic process is a very efficient method to produce multi-wall carbon nanotubes $[1,2]$. The first two techniques allow the production of SWNTs in high quantities [3,4]. Many previous reports [5-10] have shown that the catalytic way could be a possibility to produce nanotubes on a large scale at a very low cost.

Biro et al. [5] reported the presence of SWNTs by scanning tunneling microscopy (STM) during the

\footnotetext{
* Corresponding author. Fax: +32-81-72-46-00; e-mail: jean-francois@fundp.ac.be
}

synthesis of multi-wall nanotubes by catalytic decomposition of hydrocarbons.

Peigney et al. [6] also reported the synthesis of a mixture of single- and multi-wall nanotubes by decomposition of $\mathrm{H}_{2} / \mathrm{CH}_{4}$ on $\mathrm{Fe}$ alumina nanocomposite powders.

Isolated single-wall tubes have also been synthesised by the disproportionation of $\mathrm{CO}$ on $\mathrm{Mo}$ nanoparticles [7] and more recently, by chemical vapor deposition of methane on supported $\mathrm{Fe}_{2} \mathrm{O}_{3}$ catalysts [8]. Finally, the production of SWNTs including double-wall nanotubes (DWNTs) on Mo and Mo-Fe alloy has also been reported [9]. By this method, the choice of the support and the metals or metal mixtures seems be determinant in the SWNTs synthesis. Colomer et al. [10] have shown the 
presence of SWNTs for different metal pairs (Fe, Co, $\mathrm{Ni}$, binary mixture, ...)/support (silica and alumina) with varying efficiency, depending on the system used. The abundance of SWNTs seems to increase when binary alloy nanoparticles, for the same metals, are used as in the case described by Flahaut et al. [11]. The main inconvenient of this method is to estimate the yield of the reaction in SWNTs because of the presence of catalyst and the other forms of carbon (multi-wall nanotubes (MWNTs), amorphous carbon, carbon nanospheres, ...).

As a conclusion, in all cases described in the literature, the synthesis of SWNTs seems to be linked to the very small size of the catalyst particles. A mechanism for the nucleation of both single- and multi-wall nanotubes obtained by CCVD from catalytic particles has already been reported $[7,10]$.

Note that pyrolisis of hydrocarbons with metallocenes has also been successfully applied for the production of SWNTs [12,13] in large quantities, but this way does not use the metal-supported catalysts, like the others described above.

Finally, very recent works $[14,15]$ have reported what could be a real improvement in the low-cost, large scale synthesis of SWNTs: a carbon nanotubes $/ \mathrm{Co} / \mathrm{MgO}$ composite powder was prepared by reduction of $\mathrm{Mg}_{0.9} \mathrm{Co}_{0.1} \mathrm{O}$ solid solution in $\mathrm{H}_{2} / \mathrm{CH}_{4}$ atmosphere $\left(18 \mathrm{~mol} \% \mathrm{CH}_{4}, 1000^{\circ} \mathrm{C}\right)$ to produce both single- and multi- (double-) wall carbon nanotubes in a 1:1 ratio. The carbon nanotubes were extracted by dissolution of $\mathrm{MgO}$ and part of the Co catalyst in the $\mathrm{HCl}$ aqueous solution (36\% room temperature). Indeed, $\mathrm{MgO}$ presents the advantage over other supports such as alumina, spinel and silica that it can be readily dissolved in acids. It was reported $[14,15]$ that the mild acid treatment does not damage the carbon nanotubes, more than $80 \%$ of which are either SWNTs or DWNTs.

In the present work, we describe the large-scale synthesis of SWNTs over supported catalyst Metal $/ \mathrm{MgO}$ where Metal is $\mathrm{Co}, \mathrm{Ni}, \mathrm{Fe}$ and a binary mixture $\mathrm{Co}-\mathrm{Fe}$. The possibility to obtain a sample containing high yields of SWNTs (70-80\%), by this way is an improvement. This fact is explained by the synthesis conditions, which allow the formation of SWNTs in abundance (which some double-wall nanotubes), and by the use of the support such as $\mathrm{MgO}$ known to be easily removed by an acidic treatment ( $\mathrm{HCl})$. Using the transmission electron microscopy (TEM), the quality of the SWNTs and the nature of contaminating phase were checked. The SWNTs were also characterized by Raman spectroscopy.

\section{Experimental}

The different catalysts are prepared by impregnation of $\mathrm{MgO}$ (Vel) with ethanol solution of metal salts $(\mathrm{Co}, \mathrm{Ni}, \mathrm{Fe})$ or a mixture of metal salts $(\mathrm{Co}-\mathrm{Fe})$ in the appropriate concentration. The material is sonicated during one hour and the ethanol is removed via a rotary evaporator. Then, the material is dried at $130^{\circ} \mathrm{C}$ during $12-15 \mathrm{~h}$ and ground into a fine powder. Finally, a portion of each catalyst was hydrogenated in $\mathrm{H}_{2} / \mathrm{N}_{2}\left(\mathrm{H}_{2}\right.$ flow: $30 \mathrm{ml} \mathrm{min}^{-1}, \mathrm{~N}_{2}$ flow: $80 \mathrm{ml} \mathrm{min}^{-1}$ ).

The synthesis of SWNTs was carried out in a fixed-bed reactor (quartz tube of $50 \mathrm{~mm}$ diameter, 80 $\mathrm{cm}$ in length in a carbolite horizontal reactor) at $1000^{\circ} \mathrm{C}$, with a typical reaction time of $10 \mathrm{~min}$. For each synthesis, a quartz boat containing about $1 \mathrm{~g}$ of catalyst was placed in the center of the reactor. The carbon source was methane with hydrogen as carrier gas, and the flows of the mixture methane/hydrogen were $75 / 300 \mathrm{ml} \mathrm{min}{ }^{-1}$. After the reaction, the catalyst (support and metal particles) is removed by acidic treatment in concentrated hydrochloric acid. Typically, the crude sample (about $1 \mathrm{~g}$ ) is placed in $50 \mathrm{ml}$ of concentrated $\mathrm{HCl}$ under sonication for 15 min. It is filtered through an HPLC filter (FP-Vericel membrane filter, porosity $0.2 \mu \mathrm{m}$ ) washed with distilled water to fix the $\mathrm{pH}$ at 6-7 and finally, dried at $130^{\circ} \mathrm{C}$.

After this purification, the carbon yield can be calculated as follows:

Carbon yield $(\%)=100\left(m_{\text {pure }} / m_{\text {crude }}\right)$,

where $m_{\text {crude }}$ is the weight of the sample after production of SWNTs, and $m_{\text {pure }}$ the weight of the sample after acidic treatment.

Finally, the sample for TEM was prepared by sonication of about $3 \mathrm{mg}$ of material in ethanol and a 


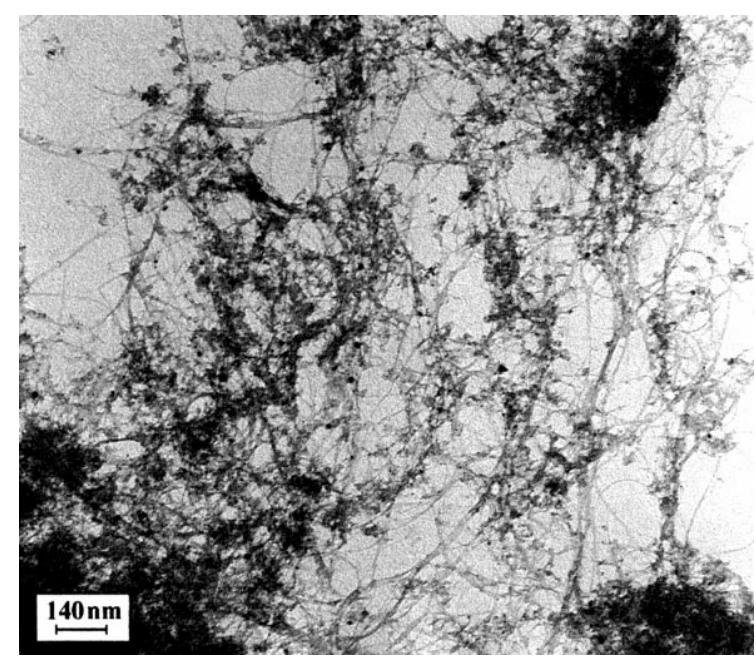

Fig. 1. Low-resolution image of abundant carbon filaments produced on $\mathrm{Co}(2.5 \%$ wt) $/ \mathrm{MgO}$ catalyst.

few drops were put onto a holey-carbon TEM grid. The quality of the sample was characterised by transmission electron microscopy.

Raman experiments have been performed with a Raman spectrophotometer Jobin Yvon T64000 in ambient atmosphere and at room temperature. The spectra are recorded using a red excitation line (676.4 $\mathrm{nm})$.

\section{Results and discussion}

Observations by low-resolution microscopy (TEM: Philips CM 20) show entangled carbon filaments and the abundance is very high in all the observed samples (Fig. 1). From several TEM images, the yield of these filaments can be estimated approximately to be of the order of $70-80 \%$, depending on the catalyst used. High-resolution transmission electron microscopy (HREM using a JEOL 200 CX) images of the sample show that each filament consists of bundles of SWNTs but confirm also the presence of isolated SWNTs in a large quantity (Figs. 2 and 3). One of these SWNTs bundles, forming crystallite-like entities organized in a two-dimensional lattice, is shown in Fig. $3 b$.

Moreover, the diameter of the SWNT can be measured by transmission electron microscopy. Typically, the diameters of isolated SWNTs are 1-5 nm. For the SWNTs aligned in the bundles, the diameter values vary between 0.8 and $2 \mathrm{~nm}$, and the estimated diameters distribution is larger than those synthe-

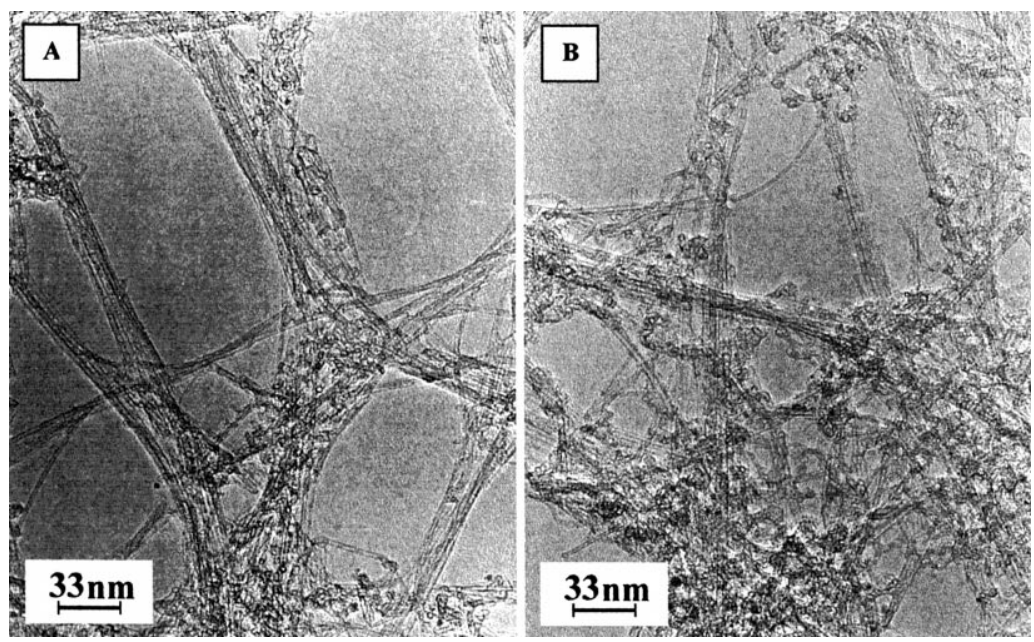

Fig. 2. (A) and (B). High-resolution images of carbon filaments produced on $\mathrm{Co}(2.5 \% \mathrm{wt}) / \mathrm{MgO}$ catalyst showing that these filaments are ropes of SWNTs. 

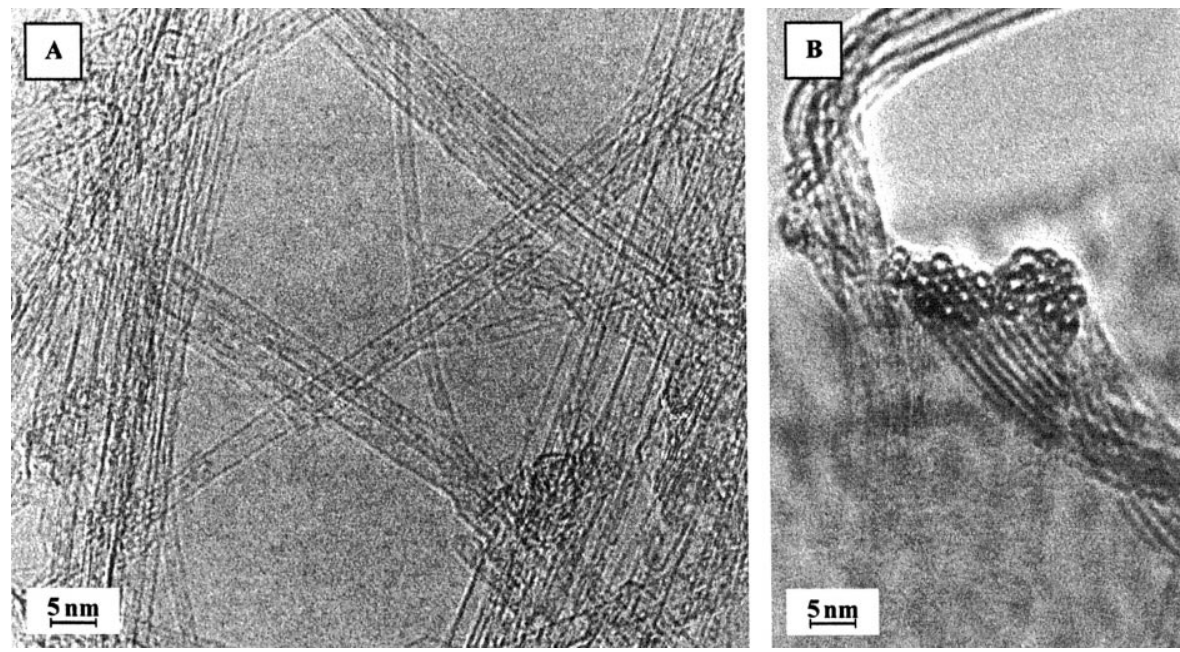

Fig. 3. Higher-resolution images of (A) SWNTs organized in bundles or isolated synthetised on $\mathrm{Co}(2.5 \% \mathrm{wt}) / \mathrm{MgO}$ catalyst, and (B) cross-section of SWNTs bundle showing the triangular lattice arrangement.

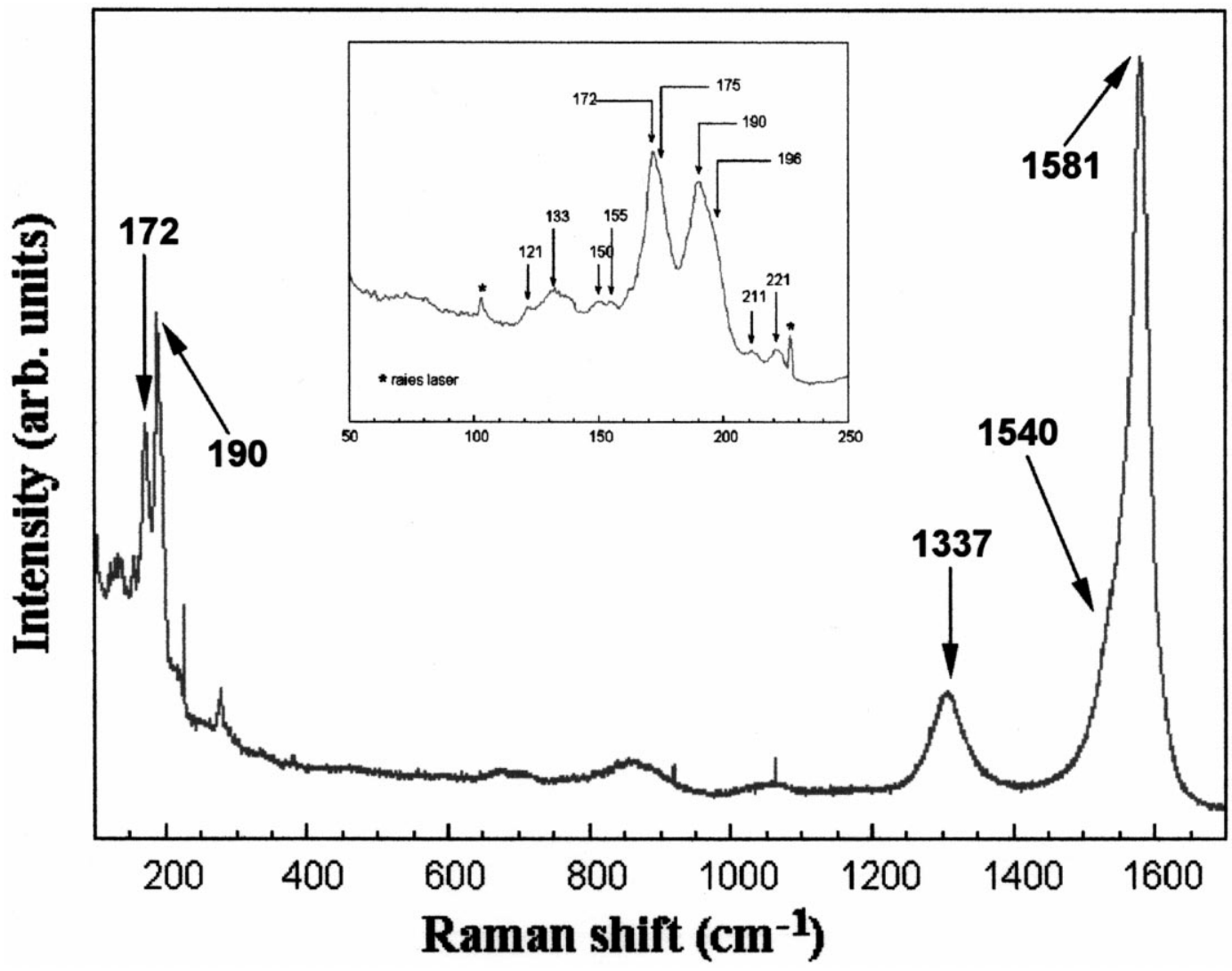

Fig. 4. Raman spectrum of SWNTs (on $\mathrm{Co}(2.5 \% \mathrm{wt}) / \mathrm{MgO}$ catalyst) recorded at room temperature, using an excitation wavelength of 676.4 $\mathrm{nm}$. Inset: the low-frequency range $\left(50-250 \mathrm{~cm}^{-1}\right)$ has been given in detail. 
sised by arc discharge or laser evaporation. The SWNTs diameters were also studied in detail using Raman spectroscopy (Fig. 4). The spectrum exhibits unambiguously the characteristic frequencies of SWNTs, but the corresponding bands (low (100-250 $\mathrm{cm}^{-1}$ ) and high (1500-1600 $\mathrm{cm}^{-1}$ ) frequencies) are reduced by the presence of other carbon forms like multi-wall nanotubes or amorphous carbon (1337 $\mathrm{cm}^{-1}$, band D). The high-frequency bands can be decomposed in one main peak around $1581 \mathrm{~cm}^{-1}$, with a shoulder around $1540 \mathrm{~cm}^{-1}$. This shoulder is more important in the case of SWNTs produced by arc discharge, where a separate peak can be observed [4]. The high-resolution spectrum obtained in the low-frequency domain shows several components at $121,133,150,155,172,175,190,196,211,221$ $\mathrm{cm}^{-1}$. The spectrum in this frequency domain is very sensitive to the tube diameters, where the frequency increases with decreasing tube diameter $(d)$. Moreover, these bands are due to $\mathrm{A}_{\mathrm{g}}$ symmetry mode where $\nu\left(\mathrm{cm}^{-1}\right)=2238 / d \AA[16]$ and the results reflect a distribution in diameters. Then, SWNTs with small diameters can be observed with the characteristic bands $211,221 \mathrm{~cm}^{-1}$, where the diameters 10.6 and $10.1 \AA$ are calculated from the formula above.

The so characterized sample, by Raman spectroscopy and by HREM, shows also the presence of small amounts of impurities like MWNTs (which are often double-wall nanotubes), metal particles encapsulated in the nanotubes or in polyhedral graphitic nanoparticles and amorphous carbon and seems to be less pure than those produced by the other techniques.

In the sample, the SWNTs tips are observed for isolated SWNTs and catalyst particles can be present or not in the tube tip (Fig. 5). This fact is in agreement with the suggested mechanism, where the growth mechanism of isolated SWNTs is close to that of the MWNTs in the CCVD process, and the diameter of the SWNT is determined by the size of the catalytic metal particle attached to their end $[7,10]$. The large diameter distribution of isolated SWNTs is also explained by this fact.

The dispersion of metal on the support surface influences the metal particle size and hence the presence of isolated SWNTs or SWNTs bundles. The bigger metal particles $(>15-20 \mathrm{~nm})$ are not active

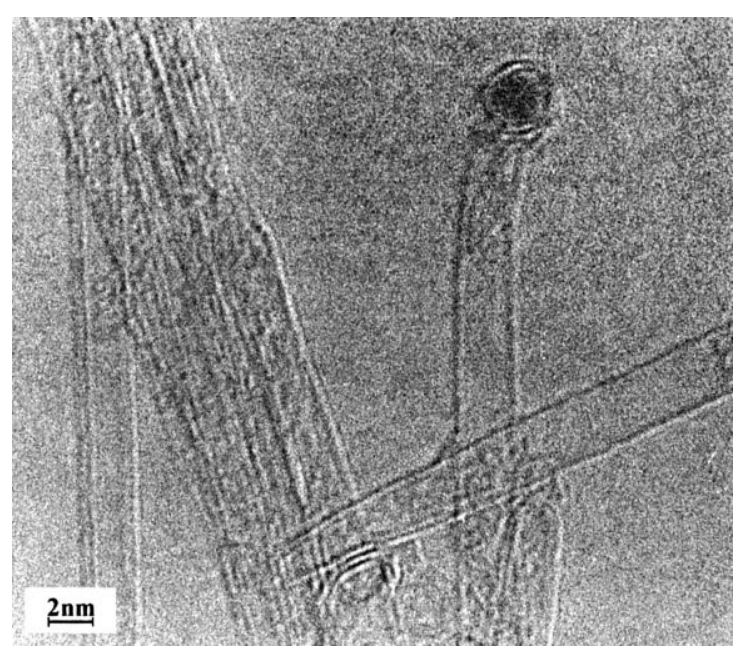

Fig. 5. High-resolution image of single-wall carbon nanotube with a small catalytic particle encapsulated to the tip. Double-wall carbon nanotube can be observed on the left of the picture (this sample was produced on $\mathrm{Co}(2.5 \% \mathrm{wt}) / \mathrm{MgO}$ catalyst $)$.

in the synthesis of SWNTs and are often found encapsulated by several graphitic layers. All the other metal particles, having a size smaller than that of the big particles are active in the synthesis of SWNTs bundles. The hypothesis of SWNTs bundles growth is that each SWNTs bundle grow from a single metal particle.

Concerning the catalysts, the nature of support (commercial magnesium oxide) is very important because it is easily removed and this fact allows one to estimate the yield of the reaction and to characterize with more precision the nature of carbon deposit: quality of SWNTs, nature of impurities, etc. It is the main advantage of this support with respect to the other supports used in the synthesis of SWNTS like alumina or silica.

For the catalysts used (Table 1), the activity seems be dependent on the nature of metal, but in all cases and for the two different preparations (hydrogenated or not), the yield is around $7 \%$, except for the $\mathrm{Ni}$ catalysts where the yield is very low $(<1 \%)$. The best activity found is for the catalyst prepared with the $\mathrm{Co}-\mathrm{Fe}$ mixture. But in this case (presence of $\mathrm{Fe}$ ) and so for the $\mathrm{Fe}$ catalysts, the impurities like MWNTs and encapsulated metal particles seem to be more abundant than with the Co catalysts. Moreover, when the weight percent of metal increases (from 2.5 
Table 1

Yields of SWNTs synthesis depending on the catalysts used

\begin{tabular}{llll}
\hline $\begin{array}{l}\text { Metals } \\
\text { used }\end{array}$ & $\begin{array}{l}\text { Weight } \\
\text { percent } \\
\text { of metal }\end{array}$ & $\begin{array}{l}\text { Yields for } \\
\text { as prepared } \\
\text { catalyst }\end{array}$ & $\begin{array}{l}\text { Yields for } \\
\text { hydrogenated } \\
\text { catalyst }\end{array}$ \\
\hline $\mathrm{Co}$ & $2.5 \%$ & $5.5 \%$ & $5.7 \%$ \\
& $5 \%$ & $6.5 \%$ & $4.7 \%$ \\
$\mathrm{Fe}$ & $2.5 \%$ & $6 \%$ & $5.9 \%$ \\
$\mathrm{Co}-\mathrm{Fe}$ & $5 \%$ & $5.8 \%$ & $5 \%$ \\
\hline
\end{tabular}

to $5 \%$ ), the yields are similar, but the quality of the samples seems to be different, because the increase of the metal content in the catalyst increases the encapsulation of metal in the graphitic nanoparticles and hence the quantity of SWNTs is smaller.

The conditions of SWNTs production, i.e., methane used as hydrocarbon, hydrogen as carrier gaz, reaction time $(10 \mathrm{~min})$ and temperature $\left(1000^{\circ} \mathrm{C}\right)$ allow the formation of SWNTs containing only a small amount of amorphous carbon and polyhedral graphitic nanoparticles. In fact, the reason to produce mainly SWNTs in abundance in the present work is the constant reaction temperature $\left(1000^{\circ} \mathrm{C}\right)$ during the reaction. It is possible that under other reaction conditions [14,15], i.e., increasing (until $1000^{\circ} \mathrm{C}$ ) and decreasing the reaction temperature, under $\mathrm{H}_{2} / \mathrm{CH}_{4}$, multi-wall carbon nanotubes could be produced when the temperature is between 800 and $1000^{\circ} \mathrm{C}$.

\section{Conclusion}

We have shown that the large-scale production (1 $\mathrm{g} \mathrm{day}^{-1}$ ) of single-wall carbon nanotubes (SWNTs) is possible by CCVD method similar to the two other techniques used until now, arc discharge and laser evaporation. Indeed, the method using the catalytic decomposition of methane over well-dispersed metal particles supported on $\mathrm{MgO}$ at $1000^{\circ} \mathrm{C}$ has been adapted to produce large quantities of SWNTs. The synthesis yield was easily estimated, after removing the support by a simple acidic treatment to obtain a product containing SWNTs of high purity. The SWNTs content in the purified samples was estimated approximately to be of the order of $70-80 \%$.
For a $10 \mathrm{~min}$ reaction, we obtain around $50 \mathrm{mg}$ of carbon deposit and for 20 reactions day ${ }^{-1}$, the daily production is of about $1 \mathrm{~g}$ of product containing essentially SWNTs. This method of synthesis could replace the other two techniques of SWNTs production, because of the lower temperature used $\left(1000^{\circ} \mathrm{C}\right)$, of the low cost of production and of its industrial application potential.

In the near future, the purification of SWNTs produced by this way will be optimised to obtain pure SWNTs in large quantities.

\section{Acknowledgements}

The authors are grateful to the European Commission, TMR contract NAMITECH, ERBFMRXCT96-0067 (DG12-MIHT) and thank the Belgian Programme on Inter University Poles of Attraction initiated by the Belgian State, Prime Minister's Office of Science Policy Programming (4/10).

\section{References}

[1] M.J. Yacaman, M.M. Yoshida, L. Rendon, J.G. Santiesteban, Appl. Phys. Lett. 62 (1993) 202.

[2] V. Ivanov, A. Fonseca, J. B.Nagy, A. Lucas, D. Bernaerts, X.B. Zhang, Carbon 33 (1995) 1727.

[3] A. Thess, R. Lee, P. Nikolaev, H.J. Dai, P. Petit, J. Robert, C.H. Xu, Y.H. Lee, S.G. Kim, A.G. Rinzler, D.T. Colbert, G.E. Scuseria, D. Tomanek, J.E. Fisher, R.E. Smalley, Science 273 (1996) 483.

[4] C. Journet, W.K. Maser, P. Bernier, A. Loiseau, M.L. De La Chapelle, S. Lefrant, P. Deniart, R. Lee, J.E. Fisher, Nature 388 (1997) 756.

[5] L.P. Biro, S. Lazarescu, Ph. Lambin, P.A. Thiry, A. Fonseca, J. B.Nagy, A.A. Lucas, Phys. Rev. B 56 (1997) 12490.

[6] A. Peigney, Ch. Laurent, F. Dobigeon, A. Rousset, J. Mater. Res. 12 (1997) 613.

[7] H. Dai, A.G. Rinzler, P. Nikolaev, A. Thess, D.T. Colbert, R.E. Smalley, Chem. Phys. Lett. 260 (1996) 471.

[8] J. Kong, A.M. Cassell, H. Dai, Chem. Phys. Lett. 292 (1998) 567.

[9] J.H. Hafner, M.J. Bronikowski, B.R. Azamian, P. Nikolaev, A.G. Rinzler, D.T. Colbert, A. Smith, R.E. Smalley, Chem. Phys. Lett. 296 (1998) 195.

[10] J.-F. Colomer, G. Bister, I. Willems, Z. Konya, A. Fonseca, G. Van Tendeloo, J. B.Nagy, Chem. Commun. (1999) $1343-$ 1344.

[11] E. Flahaut, A. Govindaraj, A. Peigney, Ch. Laurent, A. Rousset, C.N.R. Rao, Chem. Phys. Lett. 300 (1999) 236. 
[12] H.M. Cheng, F. Li, G. Su, H.Y. Pan, L.L. He, X. Sun, M.S. Dresselhaus, Appl. Phys. Lett. 72 (25) (1998) 3282.

[13] B.C. Satishkumar, A. Govindaraj, R. Sen, C.N.R. Rao, Chem. Phys. Lett. 293 (1998) 47.

[14] Ch. Laurent, A. Peigney, E. Flahaut, R.R. Basca, A. Rousset, in: D. Tomanek, R. Enbody (Eds.), Proceedings of NT99,
Science and Application of Nanotubes, Kluwer, Dordrecht, pp. $153-170$, in press.

[15] E. Flahaut, A. Peigney, Ch. Laurent, A. Rousset, J. Mater. Chem. 10 (2000), in press.

[16] S. Bandow, S. Asaka, Y. Saito, A.M. Rao, L. Grigorian, E. Richter, P.C. Eklund, Phys. Rev. Lett. 80/17 (1998) 3779. 